\title{
Vias para Nutrição Artificial na Criança (II): Acessos Parentéricos
}

\author{
Artificial Nutrition in Children (II): Parenteral Access
}

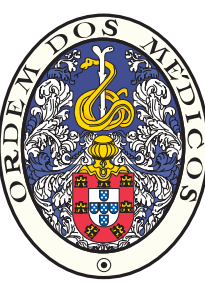

\author{
José ESTEVÃO-COSTA 1
}

Acta Med Port 2014 Nov-Dec;27(6):767-774

\section{RESUMO}

A nutrição artificial por via parentérica é de crucial importância quando a utilização do trato gastrointestinal não é exequível. Neste artigo é revista a literatura relevante acerca das principais técnicas para acessos parentéricos na criança, suas indicações, princípios de colocação e manutenção, e complicações. A escolha do tipo de acesso venoso é baseada, sobretudo, na duração prevista para a nutrição parentérica e no peso/estatura corporal. O acesso periférico é viável e vantajoso para a nutrição parentérica de curta duração (< 2 semanas); um cateter venoso central tunelizado (Broviac) é geralmente necessário na nutrição parentérica de longa duração (> 3 semanas); a colocação periférica de um cateter central é uma alternativa de utilização crescente. Os acessos parentéricos são eficazes e seguros, embora com morbi-mortalidade não desprezível sobretudo nos casos de intestino curto. A maioria das complicações está relacionada com a colocação e cuidados de manutenção dos acessos venosos, podendo ser em grande parte evitadas se os procedimentos forem efetuados por pessoal experiente com protocolos estritos.

Palavras-chave: Criança; Nutrição Parentérica; Cateterismo Venoso Central; Cateterismo Periférico.

\section{ABSTRACT}

Parenteral nutrition is crucial when the use of the gastrointestinal tract is not feasible. This article addresses the main techniques for parenteral access in children, its indications, insertion details and maintenance, and complications. The type of venous access is mainly dictated by the expected duration of parenteral nutrition and by the body weight/stature. The peripheral access is viable and advantageous for parenteral nutrition of short duration ( $<2$ weeks); a tunneled central venous catheter (Broviac) is usually necessary in long-term parenteral nutrition ( $>3$ weeks); a peripherally introduced central catheter is an increasingly used alternative. Parenteral accesses are effective and safe, but the morbidity and mortality is not negligible particularly in cases of short bowel syndrome. Most complications are related to the catheter placement and maintenance care, and can be largely avoided when the procedures are carried out by experienced staff under strict protocols.

Keywords: Child; Parenteral Nutrition; Catheterization, Central Venous; Catheterization, Peripheral.

\section{INTRODUÇÃO}

Quando a utilização do trato gastrointestinal é impossível, inadequada ou comporta graves riscos torna-se imperioso o recurso à nutrição artificial por via parentérica. Esta é uma decisão a ser avaliada individualmente e apenas deverá ser implementada se o benefício da melhoria do estado nutricional for compensador face ao risco de complicações graves da nutrição parentérica (NP).

Após os estudos de Dudrick et al ${ }^{1,2}$ realizados nos finais da década de 60 , terem demonstrado que era possível obter crescimento na criança pelo recurso à NP, assistiu-se a uma rápida e crescente utilização desta modalidade terapêutica. Tal resultou na necessidade de se dispor de vias de acesso venoso central, sobretudo nos casos com indicação para NP prolongada. Embora a utilização inicial de cateteres de 'plástico' permitisse bons acessos venosos centrais, a NP estava limitada ao uso de curta duração em regime de internamento devido às altas taxas de complicações. A procura de alternativas eficazes para o acesso venoso de longa duração foi coroada de êxito em 1973, por Broviac et al, ${ }^{3}$ através da utilização de um tipo de cateter inovador, o qual foi posteriormente modificado por Hickman et al. ${ }^{4}$ Atualmente, o âmbito da NP deixou de estar confinado à enfermaria e abrange um amplo grupo de situações em regime de ambu- latório e domiciliário, o que implicou um aumento significativo dos profissionais envolvidos nas tarefas assistenciais e de formação a crianças em NP e respetivos cuidadores.

\section{TIPOS E TÉCNICAS DE ACESSOS \\ Acesso Periférico versus Acesso Central}

A escolha do tipo de acesso venoso depende, essencialmente, da duração prevista da NP (Tabela 1). ${ }^{5}$ Para uma duração inferior a 10-14 dias o acesso venoso periférico é exequível e vantajoso. A utilização de cateteres centrais introduzidos perifericamente (PICC, epicutâneo-cava) é extremamente bem tolerada e pode manter-se eficaz por várias semanas ou meses (Fig. 1). ${ }^{6}$ Quando a indicação para NP é prolongada torna-se geralmente necessária a colocação de um cateter central tunelizado (Fig. 2); para indicações de duração mais curta (2-3 semanas), um cateter central não tunelizado é uma alternativa válida (Fig. 3).

\section{Acesso Venoso Periférico}

ANP é passível de ser realizada por uma veia periférica com as vantagens inerentes à simplicidade técnica, à segurança e ao risco de sépsis significativamente menor que a NP por cateter central. ${ }^{7}$

1. Serviço de Cirurgia Pediátrica. Hospital São João/Faculdade de Medicina. Universidade do Porto. Porto. Portugal.

Recebido: 02 de Março de 2014 - Aceite: 11 de Agosto de 2014 | Copyright @) Ordem dos Médicos 2014 
Tabela 1 - Tipo de acesso versus duração da nutrição parentérica (NP).

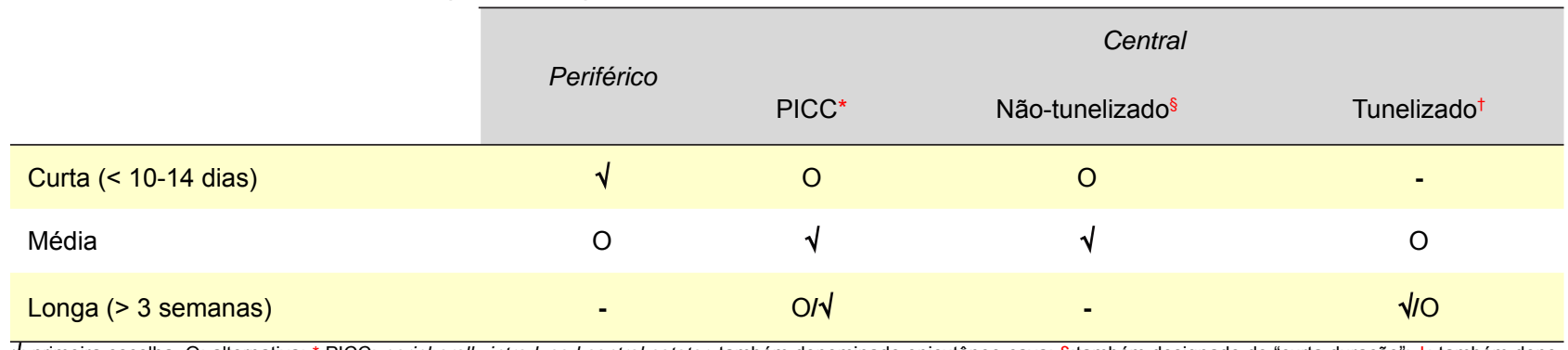

ฟ: primeira escolha, O: alternativa; * PICC: peripherally introduced central cateter, também denominado epicutâneo-cava; §:também designado de "curta duração"; †: também denominado Broviac ou Broviac-Hickman.

Cateteres/Vias de inserção/Localização - Utilizam-se geralmente cateteres de polivinil ou poliuretano por via percutânea ('por fora da agulha'). A colocação por desbridamento tem sido progressivamente abandonada e é desprovida de interesse no contexto da NP. As veias periféricas utilizadas com maior frequência são as do dorso da mão e do pé, antebraço, a safena ao nível do tornozelo e afluentes, e as epicranianas (sobretudo a temporal, no lactente). Alternativamente podem usar-se as veias da fosseta antecubital, embora devam ser preferencialmente reservadas para colheitas. A jugular externa seria um acesso excelente não fora a dificuldade da sua fixação e manutenção.

O cateterismo venoso periférico apresenta inconvenientes decorrentes do reduzido calibre vascular, como sejam o ritmo de infusão limitado, a flebite e o extravasamento (com eventual queimadura e necrose circundante). ${ }^{7}$ A necessidade de substituição é bastante frequente; no entanto, não existem argumentos sólidos para se estabelecer um intervalo rígido para a sua substituição ( 2 em 2, 3 em 3 dias), sendo preferível substituí-lo apenas, mas imediatamente, após o início daquelas complicações. A esclerose das veias e a flebite estão relacionadas com a osmolalidade, sendo expetável quando as infusões periféricas excedem os 600 mOsm. ${ }^{8} \mathrm{O}$ cateterismo venoso periférico acaba assim por ter um uso restrito no âmbito da NP, sendo extremamente difícil de manter em prematuros ou para além das duas semanas de duração.

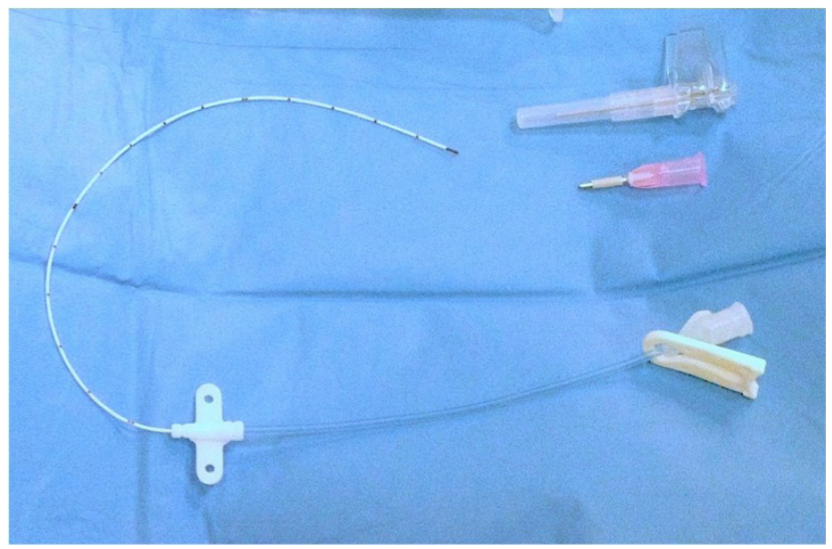

Figura 1 - Epicutaneo-cava/PICC (Nutriline 2Fr, Vygon).

\section{Acesso Venoso Central}

Apesar de requerer meios humanos com experiência, das maiores exigências em termos logísticos e das potenciais complicações, o acesso venoso central é praticamente imprescindível na NP, sobretudo quando prolongada. À possibilidade de administração de infusões hiperosmolares, acrescem a superior longevidade e a melhor tolerância comparativamente aos acessos periféricos.

Acesso direto versus acesso à distância - É possível aceder a uma veia central abordando-a diretamente (eventualmente uma tributária imediata) situação que designamos por cateter venoso central (CVC), ou fazendo progredir um cateter introduzido numa veia periférica (PICC). O PICC pretende aproveitar as vantagens do acesso periférico e obviar as complicações do acesso direto às veias centrais. No entanto, o acesso direto apresenta virtudes tais como permitir a utilização de cateteres mais curtos e viabilidade de colocação mesmo em estados de hipovolémia (pela patência das veias centrais).

Tipo de cateter - Os cateteres centrais diferem, entre outros, quanto à composição, calibre e número de lúmens. A composição determina a consistência e influencia o potencial trombogénico: os de polyvinyl e polietileno são os mais rígidos e com maior potencial trombogénico; os de silicone têm a consistência mais mole e o menor risco trombogénico; os de poliuretano têm uma consistência e risco

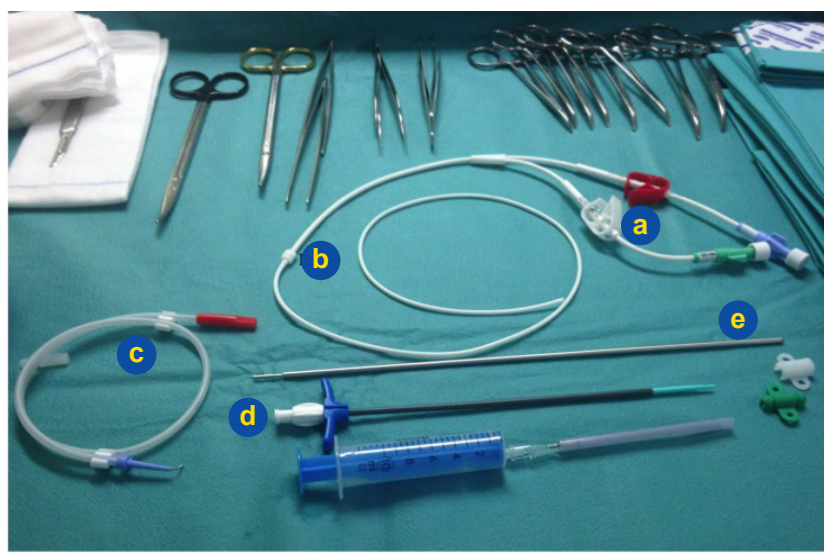

Figura 2 - CVC tipo Broviac-Hickman com kit para colocação percutânea (Lifecath-Biflux 7Fr, Vygon). a - cateter de duplo lumen; b - cuff; c - fio-guia; d - conjunto dilatador/bainha; e - introdutor/'passador'. 


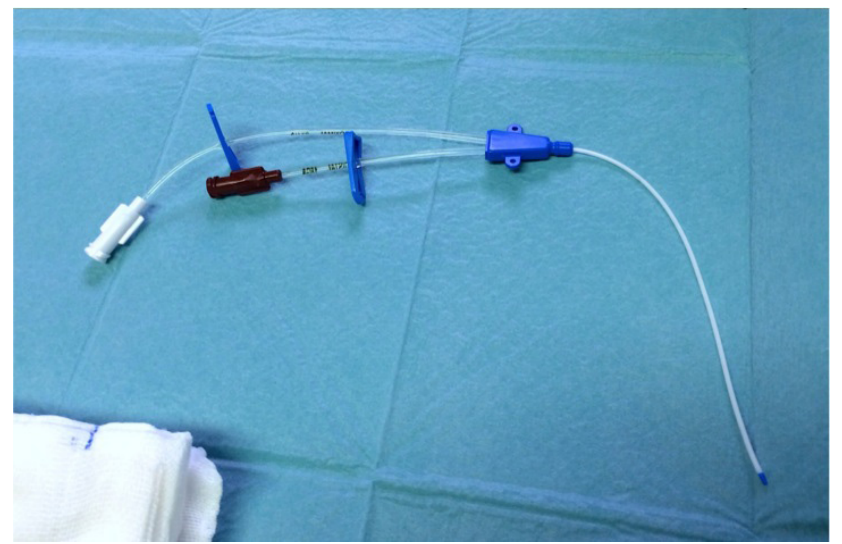

Figura 3 - CVC de curta duração de duplo lumen (Logicath ${ }^{\mathrm{TM}}$ 4Fr, Smiths Medical).

trombogénico intermédios. Existem cateteres de diversos calibres e com um, dois ou três lúmens. Nos dispositivos totalmente implantáveis, o cateter central é conectado a um reservatório colocado numa bolsa subcutânea, o qual possui uma câmara para punção epicutânea (Fig. 4).

Técnica de inserção - A colocação pode efetuar-se por desbridamento ou por punção (percutânea). O desbridamento evita algumas das complicações da punção às cegas, mas tem inconvenientes tais como deixar cicatriz, requerer aprendizagem de técnica cirúrgica e ser de execução mais demorada; no prematuro e em determinadas situações particulares é frequente o recurso ao desbridamento de veias centrais (p.e. jugular interna) ou de tributárias (p.e. facial, jugular externa, cefálica, grande safena). ${ }^{7} \mathrm{~A}$ inserção percutânea pode efetuar-se de três formas: através da agulha, método de Seldinger e método de Seldinger

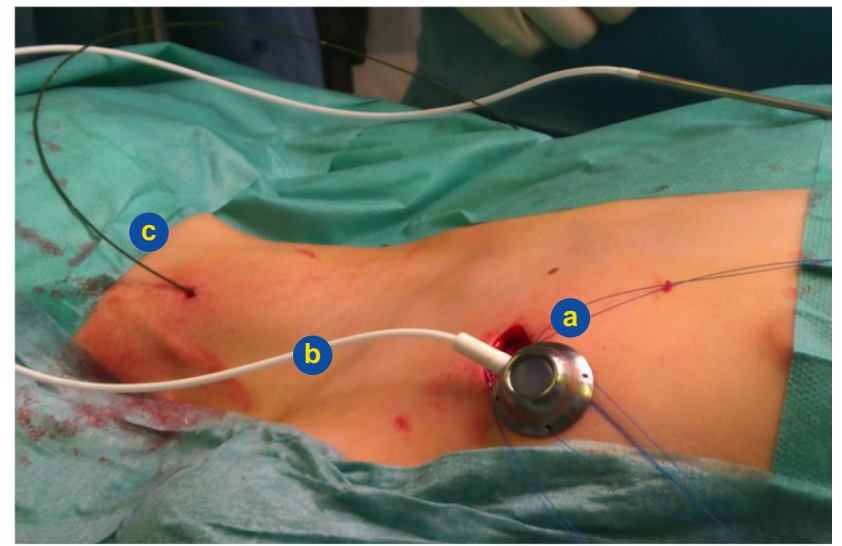

Figura 4 - CVC totalmente implantável (Mini-Sitimplant 6.6Fr, Vygon). a - reservatório com membrana/câmara de punção a ser colocado em bolsa subcutânea; b - cateter p.d.; c - fio-guia na veia jugular interna direita.

modificado. ${ }^{9} \mathrm{~A}$ inserção através da agulha, a qual se quebra longitudinalmente permitindo a sua retirada após a introdução do cateter, só é praticamente utilizada na colocação 'de forma tradicional' do PICC. No método de Seldinger, após a punção venosa, é passado um fio-guia (Fig.s 5a, 5b) sobre o qual, após a retirada da agulha, é introduzido o cateter; o seu principal inconveniente reside na limitação do binómio calibre/consistência do cateter. No método de Seldinger modificado, após a retirada da agulha é introduzida sobre o fio-guia um conjunto dilatador/bainha (Fig. 5d); de seguida retira-se o fio-guia e o dilatador e introduz-se o cateter através da bainha, a qual é retirada por abertura longitudinal da mesma (Fig. 5e); este método permite a introdução de cateteres de calibre largo e consistência mole.

Localização - Para o acesso direto, as veias mais utilizadas são a jugular interna, a subclávia, a femoral, a
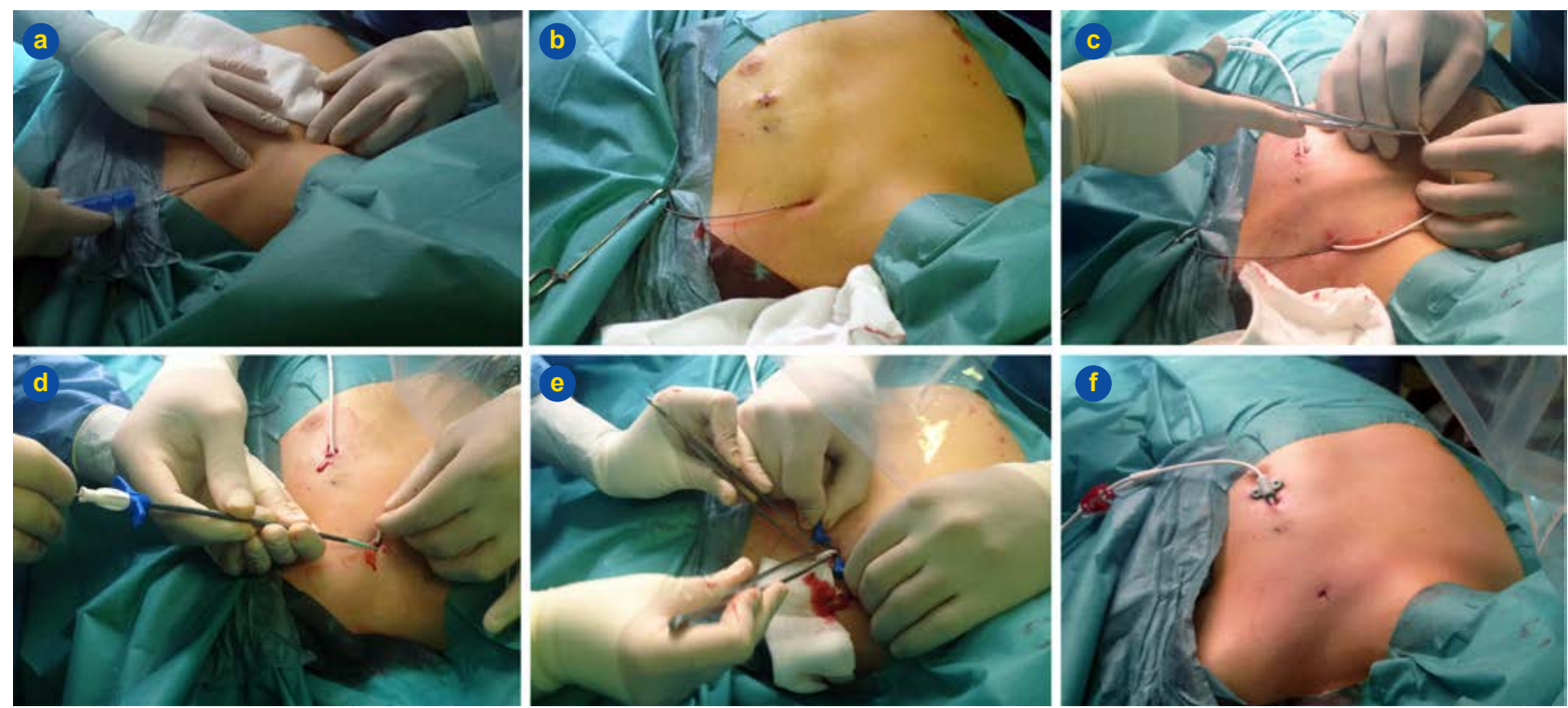

Figura 5 - Colocação de CVC tunelizado por via percutânea (método de Seldinger modificado) na veia subclávia esquerda (acesso infraclavicular). a - punção da veia; b - passagem do fio-guia através da agulha; c - tunelização do cateter até ao local da punção; $d$ - introdução do conjunto dilatador/bainha sobre o fio-guia; e - após retirada do fio-guia e dilatador, introdução do cateter pelo interior da bainha que se abre longitudinalmente até à sua exteriorização; $f$ - aspeto final. 
jugular externa e a safena a nível crural. No contexto da NP, a extensão temporal e o risco acrescido de complicações tornam necessária alguma criatividade na obtenção de outros acessos venosos. ${ }^{10-13}$

Fatores que determinam a escolha - Obviamente que o tipo de cateter condiciona a via de inserção, a qual condiciona a localização e vice-versa. Como abordado anteriormente, o principal fator a ter em linha de conta é a duração prevista de NP. A estatura (peso) é um factor importante sobretudo no recém-nascido e lactente. Determinadas situações (gerais ou locais) podem condicionar a localização, nomeadamente a presença de hipertensão intracraniana (contra-indicação relativa para a utilização da veia jugular interna). Por último, é importante a experiência de quem vai efetuar o CVC, podendo mesmo ser, dentro de certos limites, o fator determinante da escolha.

Condições prévias - A colocação de um CVC no âmbito da NP não é um procedimento para ser efetuado com caráter de urgência, e caso não seja efectuado em bloco operatório deve ser executado sob condições de assepsia cirúrgica. Se a contagem plaquetária for inferior a $50 \times 10^{\wedge} \mathrm{g} / \mathrm{L}$ (metade no caso de um PICC) deverá efetuar-se transfusão de plaquetas. ${ }^{14} \mathrm{~A}$ possibilidade de controlo radioscópico/ecográfico é decisiva para prevenir complicações durante a inserção percutânea; ${ }^{15}$ acresce que os métodos que utilizam referências anatómicas externas para posicionar a ponta do cateter têm acuidade discutível. ${ }^{7,16} \mathrm{O}$ controlo ecográfico tem inclusive vindo a revelar-se particularmente útil na identificação de veias para inserção percutânea, quer para acesso directo quer para acesso à distância. ${ }^{17-19}$

\section{PICC (epicutâneo-cava)}

Após a punção da veia periférica (p.e. antebraço, temporal), o cateter é introduzido até à junção veia cava superior (inferior)/aurícula direita, por uma das duas formas acima descritas (através da agulha ou Seldinger modificado). O PICC é particularmente útil nos recém-nascidos e constitui uma alternativa ao desbridamento da jugular interna em lactentes com peso inferior a 5-10 Kg. ${ }^{14} \mathrm{~A}$ taxa de complicações é significativamente mais baixa que, inclusivamente, com os cateteres tunelizados; o principal óbice é a alta incidência de problemas mecânicos tais como a dificuldade ou impossibilidade de progressão e a obstrução..$^{5,20}$ O PICC pode, em alternativa, ser introduzido por desbridamento (p.e. jugular externa, safena).

\section{CVC Não-Tunelizado (CVC de 'curta duração')}

Utilizam-se habitualmente cateteres em poliuretano inseridos por via percutânea utilizando o método de Seldinger (Fig.s 4 e 5a, 5b); podem ser colocados sem recurso a bloco operatório, mas a sedação influencia positivamente a taxa de êxito. ${ }^{21}$ As veias de primeira linha são a subclávia e a jugular interna e como alternativa a femoral, cujos detalhes da técnica de colocação ultrapassam o âmbito deste manuscrito.
No que respeita à veia subclávia, a escolha do lado poderá ser decidida com base na preferência individual; a punção à esquerda é mais fácil, mas comporta risco de lesão do canal torácico. ${ }^{22}$ De entre as múltiplas técnicas, a maioria dos centros preconiza o acesso infra-clavicular (Fig. 5). A observância estrita dos princípios técnicos é crucial para se evitarem complicações como pneumotórax, lesão da artéria subclávia ou mamária interna e lesão do canal torácico.

Existem múltiplas técnicas de punção da veia jugular interna, sendo mais frequentemente utilizado o acesso central. O lado direito é habitualmente preferido pelo menor risco de pneumotórax (a pleura apical é mais baixa à direita) e de punção do canal torácico, e pelo maior calibre e trajeto mais rectilíneo da jugular interna em direção à veia cava superior/aurícula direita. As principais vantagens são a facilidade da punção e a menor incidência de pneumotórax (exceto para o acesso inferior); a dificuldade de manutenção e de assepsia relacionada com a mobilidade do pescoço constituem os principais inconvenientes.

\section{CVC Tunelizado (Broviac-Hickman)}

Trata-se de cateteres em silicone (diâmetro entre 2,7Fr e $12 \mathrm{Fr}$ ), com um cuff em Dacron ${ }^{\circledR}$ (figuras 2 e 5), o qual se situará no túnel subcutâneo a uma distância variável da emergência do cateter; este cuff tem por objectivo induzir reacção fibrótica com consequente estabilização do cateter, sendo controverso o papel de barreira anti-infecciosa. ${ }^{6,23}$

$\mathrm{Na}$ colocação de cateteres tunelizados pode utilizar-se a técnica percutânea (Seldinger modificado, Fig.s 5a-5f) ou o desbridamento. A anestesia geral resulta mais cómoda para quem realiza o procedimento, mas sobretudo para a criança. No bloco operatório é possível uma melhor exposição, dispor de instrumentos próprios e as condições de assepsia são melhor asseguradas. Por via percutânea utiliza-se geralmente a veia subclávia e em alternativa a jugular interna e a femoral. Por desbridamento utiliza-se geralmente a veia jugular interna (ou externa) e como opção a safena ao nível da região crural. ${ }^{24,25}$ Embora alguns autores usem a técnica percutânea em recém-nascidos, a alta incidência de complicações da punção da veia subclávia aconselha o desbridamento da jugular interna/externa ou um PICC em recém-nascidos e lactentes com menos de $5-10 \mathrm{Kg}$.

Dispositivos totalmente implantáveis - As vantagens decorrentes de uma fácil manutenção e o benefício psicológico por permitir um padrão de vida mais normal justificam a ampla utilização destes dispositivos (Fig. 4). Não obstante, o seu uso na criança e particularmente no contexto da NP não obteve uma difusão tão grande. Na realidade, estes dispositivos apresentam alguns inconvenientes como a necessidade de punção cutânea, o risco de extravasamento, uma menor taxa de preservação perante infeção sistémica, e a fixação das agulhas (Hubber) não totalmente satisfatória. ${ }^{26}$ A necessidade de inserção e remoção sob anestesia geral e a duração limitada (até 2000 punções) são inconve- 
nientes muito relativos. ${ }^{6} \mathrm{~A}$ escolha deste sistema está assim dependente da frequência de utilização e da idade da criança.

\section{Complicações}

Cardiopulmonares - Estas são as complicações geralmente responsáveis pela mortalidade associada ao CVC. ${ }^{15}$ O pneumotórax e o hidro(hemo)tórax apresentam a maior incidência para o cateterismo da subclávia, seguindo-se em ordem de frequência a abordagem percutânea da jugular interna (Fig. 6). O pneumotórax é a complicação mais frequente ocorrendo em até $5 \%$ das tentativas de cateterismo da subclávia, pelo que se deverá efetuar uma radiografia de tórax mesmo após uma tentativa de punção sem êxito. Contudo, o controlo radiológico sistemático após colocação de um CVC com apoio radioscópico não parece justificar-se. ${ }^{27,28} \mathrm{O}$ pneumotórax pode ser assintomático e regredir espontaneamente, mas pode requerer punção aspirativa ou mesmo colocação de um tubo de toracostomia.

As arritmias devem-se à colocação do cateter na aurícula em contacto com a válvula tricúspide ou no ventrículo direito, devendo ser prevenidas pelo controlo radioscópico durante a colocação. O tamponamento cardíaco é a complicação mais grave com uma mortalidade elevada dada a dificuldade de reconhecer os sinais e sintomas precocemente, mas é extremamente raro com cateteres de silicone. O embolismo gasoso só ocorre praticamente em ventilação espontânea; a manutenção da posição de Trendelenburg durante a inserção e o cuidado na manipulação quando o cateter é aberto são importantes para a sua prevenção. ${ }^{15} \mathrm{O}$ embolismo por coágulos é geralmente secundário à remoção do cateter.

Mecânicas - As complicações mecânicas dos CVC têm uma incidência de cerca de 3,37/ 1000 dias, mas no contexto da NP são encontradas em $2 \%$ a $75 \%$ dos doentes. ${ }^{29,30}$

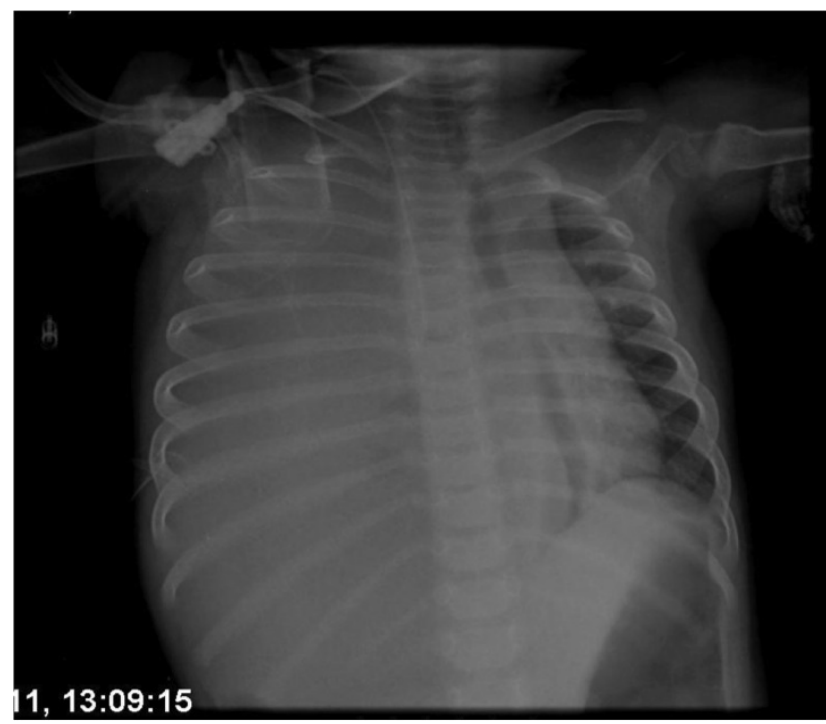

Figura 6 - Hidro(hemo)tórax massivo à direita após colocação percutânea de CVC não-tunelizado (método de Seldinger) na veia subclávia
A impossibilidade de aspiração através de um cateter pelo qual é possível perfundir pode dever-se: à formação de um agregado de fibrina à volta do cateter; a um trombo na ponta do cateter (um trombo intraluminal ocasionará obstrução à infusão); ou a um cateter encostado a um vaso ou câmara cardíaca. ${ }^{6,30}$ A obstrução por um agregado de fibrina ou trombo intraluminal pode ser ultrapassada com a instilação de doses baixas de agentes fibrinolíticos (p.e. alteplase, uroquínase, teteplase). ${ }^{30,31} \mathrm{~A}$ trombose venosa pode resultar em obstrução do cateter, mas é muito rara com cateteres de silicone; ${ }^{6}$ o tratamento varia consoante a gravidade clínica, mas a remoção do cateter e/ou administração de agentes anticoagulantes (p.e. heparina de baixo peso molecular) é geralmente eficaz. ${ }^{30} \mathrm{~A}$ incidência de trombose venosa é significativamente maior nos casos de síndroma do intestino curto que noutras causas de falência intestinal, o que pode estar relacionado com a maior taxa de complicações infeciosas. ${ }^{32,33}$

A rotura do cateter ocorre habitualmente na sua porção externa e é reparável com o auxílio de um kit próprio. A deslocação do cateter deverá ser prevenida através da utilização dos meios próprios de fixação (variável) e da fixação adicional através do penso; nos cateteres tipo Broviac é sobretudo importante nas duas primeiras semanas após colocação, enquanto o cuff ainda não está aderente.

Infeciosas - As complicações infeciosas podem ser locais (do ponto de saída ou do túnel-tunelite) ou sistémicas; a colonização do cateter define-se como a presença de hemoculturas positivas na ausência de sintomas ou sinais clínicos de infeção. As infeções locais são tratáveis numa proporção significativa de casos; a decisão de conservar o cateter (a remoção é mais frequentemente necessária na tunelite) e o tipo de tratamento deverão ser individualizados: cuidados locais e antibioterapia oral ou parentérica (se neutropenia, tunelite ou ineficácia da via oral).

A taxa de infeções sistémicas é extremamente variável dependendo, entre outros, da idade/peso da criança, da localização e tipo de cateter, da duração e da indicação, pelo que os valores podem oscilar entre 0,3 a 15 episódios (em média, 1,7) por cada 1000 dias de utilização. ${ }^{17,29,34-41} A$ taxa de infeção é mais alta em recém-nascidos e no caso de cateteres de múltiplo lúmen. A incidência de complicações infeciosas é substancialmente maior na NP, quer seja por PICC quer seja por CVC, com taxas até seis vezes superiores na síndroma de intestino curto devido à translocação bacteriana. ${ }^{36,38,42,43}$ Os microrganismos geralmente responsáveis por infeções sistémicas são: Estafilococo coagulase-negativo, Enterococo, Gram-negativos, Estafilococo aureus e Estreptococo. ${ }^{36,44,45}$

Dado que a febre é frequentemente o único sinal de sépsis, qualquer doente febril com CVC deverá ser considerado como tendo potencialmente uma sépsis relacionada com o cateter. Sem a remoção do cateter, este diagnóstico permanece uma questão controversa. Existem, contudo, métodos com acuidade relativamente alta, nomeadamente os que comparam o resultado de hemoculturas de colheitas 
periféricas com as de colheitas do CVC, a saber: o tempo para positividade (se CVC for pelo menos duas horas mais precoce) e a quantificação de colónias (uma ratio CVC/periférica igual ou superior a 3-5/1).45-48 $\mathrm{A}$ distinção entre sépsis relacionada ou não com o cateter é, não raras vezes, estabelecida clinicamente, ou seja baseada na ausência ou presença de outra origem (pulmonar, génito-urinária, gastrointestinal, feridas, etc.); o diagnóstico diferencial até nem é de crucial importância no caso dos cateteres em silicone, pois a conduta (inicial) é idêntica. Na realidade, a abordagem da sépsis relacionada com CVC depende do tipo de cateter. Um CVC não-tunelizado deve ser removido e efetuada antibioterapia sistémica durante 7-14 dias. Um CVC tunelizado pode não ser removido perante sépsis por Estafilococo coagulase-negativo ou Enterococo, sendo efectuada antibioterapia sistémica e do cateter (lock, ver adiante); a remoção do cateter está indicada se ocorrer deterioração clínica ou bacteriémia recorrente. Embora discutível, perante infeção por Estafilococo aureus, Gram negativos ou Candida deverá proceder-se à remoção imediata, exceto se não houver acessos alternativos. ${ }^{26,36,47-50} \mathrm{De}$ fato, as taxas de preservação do CVC são significativamente mais baixas na presença de trombose vascular, tunelite ou infecção por Estafilococo aureus e Candida. ${ }^{42,50}$

No que respeita à profilaxia de complicações infeciosas existem uma série de procedimentos promissores, a maioria dos quais não suficientemente validados em estudos na criança. A utilização de antibióticos durante a colocação do cateter poderá reduzir a taxa de infeção; contudo, pelo menos em recém-nascidos, não diminui significativamente a mortalidade, sendo a sua utilização considerada não justificada. ${ }^{7,48,51} \mathrm{~A}$ eficácia de dispositivos impregnados com antissépticos ou antibióticos (cateter e/ou cuff) está ainda por ser demonstrada na criança. ${ }^{48} \mathrm{O}$ uso de clorhexidina (em vez de iodopovidona) na desinfeção durante a colocação e cuidados de manutenção, assim como a utilização de pensos/esponjas impregnados com aquele antisséptico, parecem reduzir significativamente a colonização bacteriana e as complicações infeciosas sistémicas. ${ }^{48,52,53} \mathrm{~A}$ colocação de soluções antimicrobianas (p.e. etanol, antibióticos) no lúmen do cateter por um período superior a duas horas (o denominado lock) parece também diminuir significativamente a taxa de infeções sistémicas. ${ }^{37,39,41,48,54,55}$

Outras - Durante a inserção do CVC podem ainda ocorrer outras complicações tais como: punção arterial (subclávia, carótida, femoral), lesão do canal torácico, lesão do plexo braquial, paralisia do nervo frénico, laceração da veia subclávia, síndroma de Horner, síndroma da veia cava superior, hidromediastino, etc. Perante punção arterial é geralmente suficiente efetuar compressão direta durante cerca de cinco minutos; esta complicação é frequente na abordagem percutânea da jugular interna, sendo particularmente importante reconhecê-la, dado o risco de compressão traqueal pelo hematoma cervical que se pode desenvolver.

\section{Manutenção}

Qualquer manipulação de um CVC deverá obedecer a condições estritas de assepsia, nomeadamente o uso de luvas, máscara e bata ou blusão esterilizados. Deverão existir protocolos com normas sobre colheitas e administrações, 'lavagem' do sistema, desinfeção, isolamento e substituição de sistemas e conexões, e frequência e tipo de penso. ${ }^{6}$ As normas estabelecidas deverão ser supervisionadas por uma equipa multidisciplinar (enfermagem, nutrição, farmácia, etc.). Um ritmo de perfusão constante, nomeadamente por recurso a bombas perfusoras, é importante para evitar a obstrução luminal. ${ }^{6}$ Os pensos não deverão ser impermeáveis, pois acarretam um aumento significativo da colonização bacteriana cutânea. Existem uma série de factores cuja eficácia na prevenção de complicações infeciosas é controversa (p.e. frequência do penso e de substituição dos solutos e conexões, tipo de isolamento das conexões, etc.), mas que têm pelo menos o mérito de funcionar como um reforço para a importância da assepsia na manutenção do cateter.

\section{Remoção do Cateter}

A remoção do cateter é um procedimento relativamente simples, mas não deve ser menosprezado. ${ }^{56}$ No caso dos cateteres tipo Broviac é preferível extrair o cuff sob anestesia local; um aspecto importante a ter em conta é que o cateter não adere ao tecido celular subcutâneo. Os cateteres em silicone só excepcionalmente aderem ao vaso, ao contrário dos cateteres em poliuretano (p.e. CVC não-tunelizado) em que tal poderá ocorrer se permanecerem durante longos períodos de tempo. ${ }^{57}$

Após a remoção deverá ser efetuada compressão local durante 5 a 10 minutos, inspecionado o cateter para confirmar a sua extração completa, e enviada a sua ponta para exame cultural.

\section{CONCLUSÃO}

O desenvolvimento tecnológico verificado nas décadas de 80 e 90 permitiu que, atualmente, se disponha de um arsenal versátil para a colocação de vias de acesso para nutrição entérica e parentérica na criança. Na realidade, é possível estabelecer vias de nutrição artificial em virtualmente todas as situações clínicas e todas as idades (pesos/ estaturas), incluindo os prematuros de muito baixo peso. A via de acesso deverá ser eleita atendendo simultaneamente à idade, à indicação e ao tempo de utilização.

As técnicas de acesso entérico ou parentérico são eficazes e seguras. A maioria das complicações é 'iatrogénica', dado estarem relacionadas com os cuidados de colocação e manutenção, sendo por isso evitáveis..$^{15}$ Embora as complicações relacionadas com a colocação possam ser minimizadas quando esta é efetuada por pessoal experiente, só uma equipa multidisciplinar, com moral elevado e atuando com protocolos estritos, poderá otimizar os benefícios da nutrição artificial. ${ }^{58,59}$ 


\section{CONFLITOS DE INTERESSE}

O autor declara a inexistência de conflitos de interesse.

\section{FONTES DE FINANCIAMENTO}

Este trabalho não foi objecto de financiamentos ou subsídios.

ling of PVC catheters on sepsis rate. JPEN J Parenter Enteral Nutr. 1980;4:514-7.

24. Tecklenburg FW, Cochran JB, Webb SA, Habib DM, Losek JD. Central venous access via external jugular vein in children. Pediatr Emerg Care. 2010;26:554-7.

25. Zhang $\mathrm{Q}$, Jiao $\mathrm{L}$, Zhou $\mathrm{H}$. Comparison of implantable venous ports with catheter insertion via external jugular cut down and subclavian puncture in children: single center experience. Pediatr Surg Int. 2009;25:499-501.

26. Megged O, Shalit I, Yaniv I, Fisher S, Livni G, Levy I. Outcome of antibiotic lock technique for persistent central venous catheter-associated coagulase-negative Staphylococcus bacteremia in children. Eur J Microbiol Infect Dis. 2010;29:157-61.

27. Adwan $\mathrm{H}$, Gordon $\mathrm{H}$, Nicholls $\mathrm{E}$. Are routine chest radiographs needed after fluoroscopically guided percutaneous insertion of central venous catheters in children? J Pediatr Surg. 2008;43:341-3.

28. Keckler SJ, Spilde TL, Ho B, Tsao K, Ostlie DJ, Holcomb III GW, et al. Chest radiograph after central line placement under fluoroscopy: utility of futility? J Pediatr Surg. 2008;43:854-6.

29. Gandullia P, Lugani F, Costabello L, Arrigo S, Calvi A, Catellano E, et al. Long-term home parenteral nutrition in children with chronic intestinal failure: A 15-year experience at a single Italian centre. Dig Liver Dis. 2011;43:28-33

30. van Ommen $\mathrm{CH}$, Tabbers MM. Catheter-related thrombosis in children with intestinal failure and long-term parenteral nutrition: How to treat and prevent? Thromb Res. 2010;126:465-70.

31. Blaney M, Shen V, Kerner JA, Jacobs BR, Gray S, Armfield J, et al. Alteplase for the treatment of central venous catheter occlusion in children: results of a prospective, open-label, single-arm study (The Cathflo Activase Pediatric Study). J Vasc Interv Radiol. 2006;17:1745-51.

32. Raad II, Luna M, Khalil SA, Costerton JW, Lam C, Bodey GP. The relationship between the thrombotic and infectious complications of central venous catheters. JAMA. 1994;271:1014-6.

33. van Rooden CJ, Schippers EF, Barge RM, Rosendaal FR, Guiot HF, van der Meer FJ, et al. Infectious complications of central venous catheters increase the risk of catheter-related thrombosis in hematology patients: a prospective study. J Clin Oncol. 2005;23:2655-60.

34. Buckley J, Coffin SE, Lautenbach E, Prasad P, Chu J, Goyal M, et al. Outcome of Escherichia coli and/or Klebsiella bloodstream infection in children with central venous catheters. Infect Control Hosp Epidemiol. 2007;28:1308-10.

35. Pinon M, Bezzio S, Tovo PA, Fagioli F, Farinasso L, Calabrese R, et al. A prospective 7-year survey on central venous catheter-related complications at a single pediatric hospital. Eur J Pediatr. 2009;168:1505-12.

36. Greenberg RG, Moran C, Ulshen M, Smith PB, Benjamin Jr DK, CohenWolkowiez M. Outcomes of catheter-associated infections in pediatric patients with short bowel syndrome. J Pediatr Gastroenterol Nutr. 2010;50:460-2.

37. Jones BA, Hull MA, Richardson DS, Zurakowski D, Gura K, Fitzgibbons $S C$, et al. Efficacy of ethanol locks in reducing central venous catheter infections in pediatric patients with intestinal failure. J Pediatr Surg. 2010;45:1287-93.

38. Advani S, Reich NG, Sengupta A, Gosey L, Milstone AM. Central lineassociated bloodstream infection in hospitalized children with peripherally inserted central venous catheters; extending risk analyses outside the intensive care unit. Clin Infect Dis. 2011:52:1108-15.

39. Cober MP, Kosacevich DS, Teitelbaum DH. Ethanol-lock therapy for the prevention of central venous access device infections in pediatric patients with intestinal failure. JPEN J Parenter Enteral Nutr. 2011;35:6773.

40. Rey C, Alvarez F, De-La-Rua V, Concha A, Medina A, Diaz JJ, et al Intervention to reduce catheter-related bloodstream infections in a apediatric intensive care unit. Intensive Care Med. 2011;37:678-85.

41. Wales PW, Kosar C, Carricato M, de Silva N, Lang K, Avitzur Y. Ethano lock therapy to reduce the incidence of catheter-related bloodstream infections in home parenteral nutrition patients with intestinal failure: preliminary experience. J Pediatr Surg. 2011;46:951-6.

42. Kurkchubasche AG, Smith SD, Rowe MI. Catheter sepsis in short-bowel syndrome. Arch Surg. 1992;127:21-4.

43. Diamanti A, Basso MS, Castro M, Calce A, Pietrobattista A, Gambarra

. Aima MC, Falbo GH. Percutaneous subclavian cent nous catheterization in children and adolescents:
tions and related factors. J Pediatr. 2007:83:64-70.

22. Masumoto K, Uesugi T, Nagata N, Taguchi S, Ogita K, Yamanouchi T, et al. Safe techniques for inserting the hickman catheters in pediatric patients. Pediatr Hematol Oncol. 2006;23:531-40.

23. von Meyenfeldt MM, Stapert J, de Jong PC, Soeters PB, Wesdorp RI, Greep JM. TPN catheter sepsis: lack of effect of subcutaneous tunnel- 
M. Prevalence of life-thretening complications in pediatric patients affected by intestinal failure. Transplant Proc. 2007;39:1632-3.

44. Slater BJ, Krummel TM. Surgical infectious disease. In: Holcomb III GW, Murphy JP, editors. Ashcraft's Pediatric Surgery. $5^{\text {th }}$ ed. Philadelphia: Saunders Elsevier; 2010. p. 117-24.

45. Acuña M, O’Ryan M, Cofré J, Alvarez I, Benadof D, Rodriguez P, et al. Differential time to positivity and quantitative cultures for noninvasive diagnosis of catheter-related blood stream infection in children. Pediatr Infect Dis J. 2008;27:681-5.

46. Kassis C, Rangaraj G, Jiang Y, Hachem RY, Raad I. Differentiating culture samples representing coagulase-negative staphylococcal bacteremia from those representing contamination by use of time-to-positivity and quantitative blood culture methods. J Clin Microbiol. 2009;47:325560.

47. Bowen A, Carapetis J. Advances in the diagnosis and management of central venous access device infections in children. Adv Exp Med Biol. 2011;697:91-106.

48. Huang EY, Chen C, Abdullah F, Aspelund G, Barnhart DC, Calkins CM et al. Strategies for the prevention of central venous catheter infections: an American Pediatric Surgical Association Outcomes and Clinical Trials Committee systematic review. J Pediatr Surg. 2011;46:2000-11.

49. Raad I, Kassar R, Ghannam D, Chaftari AM, Hachem R, Jiang Y. Management of the catheter in documented catheter-related coagulasenegative staphylococcal bacteremia: remove or retain? Clin Infect Dis. 2009;49:1187-94.

50. Giacchino M, Bezzio G, Chiapello N, Saracco P, Fagioli F, Caviglia I, et al. Continuous antibiotic infusion for salvage therapy of partially implanted central venous catheter tunnel infections due to staphylococci. Pediatr Blood Cancer. 2007;49:1010-2.

51. Lodha A, Furlan AD, Whyte H, Moore AM. Prophylactic antibiotics in the prevention of catheter-associated bloodstream bacterial infection in preterm neonates: a systematic review. J Perinatol. 2008;28:526-33.

52. Soothill JS, Bravery K, Ho A, Macqueen S, Collins J, Lock P. A fall in bloodstream infections followed a change to $2 \%$ chlorhexidine in $70 \%$ isopropanolol for catheter connection antisepsis: a pediatric single center before/after study on a hemopoietic stem cell transplant ward. Am J Infect Control. 2009;37:626-30.

53. Bishay M, Retrosi G, Horn V, Cloutman-Green E, Harris K, De Coppi $P$, et al. Chlorhexidine antisepsis significantly reduces the incidence of sepsis and septicemia during parenteral nutrition in surgical infants. $J$ Pediatr Surg. 2011;46:1064-9.

54. Onland W, Shin CE, Fustar S, Rushing T, Wong WY. Ethanol-lock technique for persistent bacteremia of long-term intravascular devices in pediatric patients. Arch Pediatr Adolesc Med. 2006;160:1049-53.

55. Mouw E, Chessman K, Lesher A, Tagge E. Use of ethanol lock to prevent catheter-related infections in children with short bowel syndrome. J Pediatr Surg. 2008;43:1025-9.

56. Lee AC. Elective removal of cuffed central venous catheters in children Support Care Cancer. 2007;15:897-901.

57. Maizlin I, Carpentier H, Bliss D. Difficult extraction of long-term central venous catheters in children- case report. J Pediatr Surg. 2010;45:17203

58. Costello JM, Morrow DF, Graham DA, Potter-Bynoe G, Sandora TJ, Laussen PC. Systematic intervention to reduce central line-associated bloodstream infection rates in a pediatric cardiac intensive care unit. Pediatrics. 2008;121:915-23.

59. Braegger C, Decsi T, Dias JA, Hartman C, Kolacek S, Koletzko B et al. Practical approach to pediatric enteral nutrition: a comment by the ESPGHAN committee on nutrition. J Pediatr Gastroenterol Nutr. 2010;51:110-22. 


\section{Vias para Nutrição Artificial na Criança (II): Acessos Parentéricos}

Acta Med Port 2014:27:767-774

Publicado pela Acta Médica Portuguesa, a Revista Científica da Ordem dos Médicos

Av. Almirante Gago Coutinho, 151

1749-084 Lisboa, Portugal.

Tel: +351218428215

E-mail: submissao@actamedicaportuguesa.com

www.actamedicaportuguesa.com

ISSN:0870-399X | e-ISSN: 1646-0758

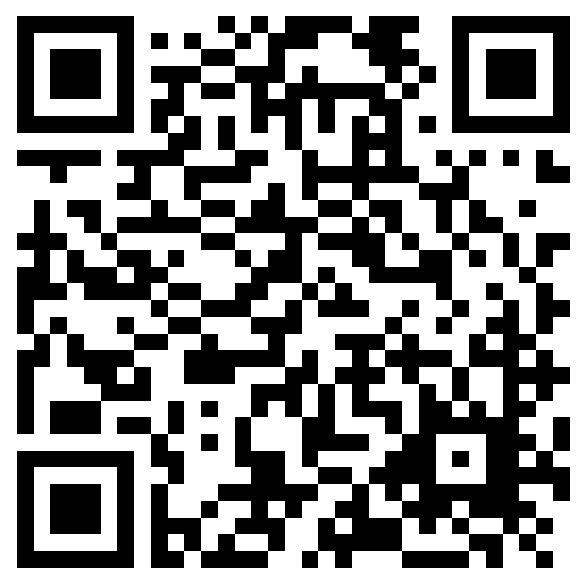

